\title{
Short communication: Investigation of antibiotic alternatives to improve health and growth of veal calves
}

\author{
J. A. Pempek, E. Holder, K. L. Proudfoot, M. Masterson, and G. Habing ${ }^{1}$ \\ Department of Veterinary Preventive Medicine, The Ohio State University, Columbus 43210
}

\begin{abstract}
The inherent disease susceptibility of veal calves results in frequent antimicrobial use. Improvements in antimicrobial stewardship necessitate alternative therapies to improve calf health and growth, while reducing the need for antimicrobials important to human health. This study investigated the effect of 2 alternative therapies, lactoferrin (an iron-binding protein found in colostrum) and cinnamaldehyde (an essential oil of the cinnamon plant) on growth, disease incidence, and mortality risk in special-fed veal calves. On the day of arrival to the growing facility ( 3 to $7 \mathrm{~d}$ of age), calves $(\mathrm{n}=80$ per treatment) were randomized to 1 of 3 treatments: (1) control (no supplement), (2) lactoferrin $(1 \mathrm{~g} / \mathrm{d}$ in milk replacer for $7 \mathrm{~d})$, or $(3)$ cinnamaldehyde $(1 \mathrm{~g} / \mathrm{d}$ in milk replacer for $21 \mathrm{~d}$ ). Body weight was measured on the day of arrival (d 0), 21, and $42 \mathrm{~d}$ postarrival. Health assessments were performed twice weekly through 21 $\mathrm{d}$, and mortality records were obtained through $6 \mathrm{wk}$ postarrival. A repeated-measures ANOVA was used to compare growth between treatment groups, and a Poisson regression model (PROC GENMOD, SAS v. 9.4, SAS Institute Inc., Cary, NC) was used to test differences between groups in the incidence of diarrhea (fecal score $\geq 2$ with and without depression and temperature) and disease through 3 wk postarrival. Body weight and average daily gain were similar between treatments. Neither lactoferrin nor cinnamaldehyde had an effect on diarrhea incidence. However, the risk of navel inflammation was significantly lower for calves that received cinnamaldehyde compared with calves in the control group. Mortality through 6 wk postarrival was low, with 4,1 , and 0 deaths from the control, lactoferrin, and cinnamaldehyde treatment groups, respectively. Additional research is needed to investigate various doses of these alternative therapies on calf health and growth, in addition to different routes of administration.
\end{abstract}

Received October 26, 2017.

Accepted January 20, 2018.

${ }^{1}$ Corresponding author: habing.4@osu.edu
Key words: calf diarrhea, growth, lactoferrin, cinnamaldehyde

\section{Short Communication}

The early management of special-fed veal calves (calves marketed at 16 or 20 wk of age; Terosky et al., 1997) presents a particular challenge to calf health and welfare. Calves often travel long distances and are co-mingled with other animals during transport and auction, likely increasing their susceptibility to disease (Taylor et al., 2010). Special-fed veal calves arrive to growing facilities with varying degrees of dehydration, depression, and navel inflammation (Pempek et al., 2017), and diarrhea and respiratory disease are leading causes of morbidity and mortality in special-fed veal calves (Pardon et al., 2013). Strategies to reduce morbidity and early mortality sometimes include prophylactic and therapeutic use of antibiotics in milk or medicated milk replacer (MR), and thus, antimicrobial use in the veal industry is higher than other animal industries (Pardon et al., 2012). Antimicrobials categorized as "highest priority critically important," including third generation cephalosporins and fluoroquinolones, are routinely used in calves to treat respiratory or enteric infections (WHO, 2017). However, recent regulations mandate that calves no longer be fed medically important antibiotics continuously in milk or MR (Mzyk et al., 2017). Thus, improved antibiotic stewardship necessitates research on alternative therapies for reducing morbidity and mortality in special-fed veal calves.

Lactoferrin, an iron-binding glycoprotein in colostrum (Rybarczyk et al., 2017), and cinnamaldehyde, a natural phenylpropanoid compound in the bark of the cinnamon tree (Chapman et al., 2017), are 2 antibiotic alternatives that have been investigated for use in livestock. Lactoferrin supplementation in pre-weaned dairy calves has been shown to increase ADG (Joslin et al., 2002; Robblee et al., 2003) and reduce diarrhea (Robblee et al., 2003) and mortality (Habing et al., 2017); however, other studies have shown no significant effect (Cowles et al., 2006). Prior studies have evaluated cinnamaldehyde supplementation and have found 
a positive effect on DMI and milk production in lactating dairy cows (cinnamaldehyde and eugenol blend; Wall et al., 2014) or no significant effect on growth in weaned dairy calves (Chapman et al., 2017). However, no data are available describing the effects of lactoferrin and cinnamaldehyde supplementation in special-fed veal calves.

The objective of this study was to investigate the effect of lactoferrin and cinnamaldehyde on the health, growth, and mortality of special-fed veal calves. We hypothesized that supplementing calves with lactoferrin and cinnamaldehyde would improve BW and ADG, reduce the incidence of diarrhea and other health outcomes, and reduce calf mortality.

This study was conducted from June through July 2016 with 2 special-fed veal cohorts ( $\mathrm{n}=120$ calves per cohort) on 1 commercial farm in Ohio, in accordance with the guidelines administered by the Institutional Animal Care and Use Committee (Animal Use Protocol: 2015A00000131). Holstein bull calves (approximately 3 to $7 \mathrm{~d}$ of age) were purchased from livestock auctions in Massachusetts, Pennsylvania, and New York, and transported to the growing facility in Ohio. Calves were managed as all-in, all-out production units, and each cohort was filled within $24 \mathrm{~h}$. Calves were housed in individual stalls $(2.13 \mathrm{~m} \times 0.61$ $\mathrm{m}$ ) with coated metal slatted flooring (Tenderfoot, Tandem Products Inc., Minneapolis, MN). Stalls were separated via removable metal dividers with horizontal partitions to provide visual access to other calves, and temperature and humidity in each room were mechanically controlled. Calves were vaccinated with Inforce 3 (intranasal; Zoetis, Parsippany, NJ) before milk feeding on the day of arrival to the growing facility. Calves were fed MR (22\% protein, $18 \%$ fat) via bucket twice daily at approximately 0500 and $1600 \mathrm{~h}$; calves received 220 $\mathrm{g}$ of MR powder reconstituted in warm water to yield $1.47 \mathrm{~kg}$ of MR per feeding on d 1, which was gradually increased to $454 \mathrm{~g}$ of MR powder reconstituted to yield $2.95 \mathrm{~kg}$ of MR per feeding on d 21. Water was offered via metal nipple.

A randomized complete block design was used where calves were randomized (Microsoft Excel, Redmond, WA) to 1 of the 3 treatment groups in blocks of 3, with a randomly assigned within-block order of treatments. The control group $(\mathbf{C O N} ; \mathrm{n}=80$ calves $)$ received MR without supplementation. The lactoferrin treatment group (LAC; $\mathrm{n}=80$ calves) received $1 \mathrm{~g}$ of lactoferrin powder (The Tatua Co-operative Dairy Company Ltd., Morrinsville, New Zealand) once daily added to the MR during the evening feeding for $7 \mathrm{~d}$ (Robblee et al., 2003). The cinnamaldehyde treatment group (CIN; $\mathrm{n}=80$ calves) received $1 \mathrm{~g}$ of cinnamaldehyde blend powder (Healthy Aging, Columbus, IN; zhang102@gmail.com), per manufacturer recommendation, once daily added to the MR for $21 \mathrm{~d}$. Eighty calves was calculated to provide sufficient power $(\beta=0.20)$ to identify significant $(\alpha=0.05)$ differences in growth and disease frequency between treatment and control groups. Eighty calves provides sufficient power assuming a final 6 -wk weight of 74 and $71 \mathrm{~kg}(\mathrm{SD}=6 \mathrm{~kg})$ in the treatment and control group, respectively $(\mathrm{SD}=6 \mathrm{~kg})$. The sample size is additionally sufficient to identify significant differences in disease frequency, assuming rates of 0.1 and 0.2 in the treatment and control groups, respectively, 5 observations per calf, and a calf-level intraclass correlation coefficient of 0.20 (Dohoo et al., 2009).

All calves ( $\mathrm{n}=240$ total calves) were assessed following arrival to the growing facility, and then twice per wk for 3 wk. Three experimenters (1 postdoctoral researcher, 2 experienced veterinary students) performed data collection. A blood sample from the jugular vein was collected from each calf directly following arrival to estimate passive transfer and packed cell volume (Pempek et al., 2017). Health assessments were conducted between 0700 and $1200 \mathrm{~h}$, following the morning milk feeding. To limit the awareness of the experimenters to treatment assignments, health assessments were conducted before treatment administration at the evening milk feeding, and treatment assignment was only identifiable on the datasheet available during administration (O'Connor et al., 2010). Although the same experimenter conducted health examinations and administered treatments, the experimenter was generally unaware of treatment assignments due to separation of treatment and outcome records, and the volume and frequency of data collection. However, the inability to achieve complete blinding may be viewed as a limitation to this study. Further, the inability to calculate intra- and inter-observer reliability is an additional limitation to our study due to the subjectivity of the health assessment.

The health assessment included rectal temperature, and scores for diarrhea (4-point scale; Lago et al., 2006), depression (5-point scale; adapted from Perino and Apley, 1998), respiratory disease (4-point scale; Lago et al., 2006), navel inflammation (4-point scale; adapted from Fecteau et al., 1997), and dehydration (skin tent test, 2-point scale; Wilson et al., 2000); see Pempek et al. (2017) for detailed scoring criteria. Scores for health outcomes were dichotomized using biologically relevant cut-off points. Health outcomes were considered clinically normal if fecal score $=0$ or 1 (normal or semiformed), depression score $=0$ or 1 (no signs of depression or noticeable depression without apparent signs of weakness), navel inflammation score $=0$ or 1 (normal, pencil-sized to the approximate width of pointer finger), and skin tent score $=0$ (skin remains tented for $\leq 4 \mathrm{~s}$ ). 
Uncomplicated diarrhea was defined as a fecal score of 2 or 3 (loose to watery) without fever or depression. Depression was defined as a depression score of 2,3 , or 4 (marked depression to moribund, unable to rise). A fever was defined as a temperature $\geq 39.4^{\circ} \mathrm{C}$. Complicated diarrhea was considered separately as diarrhea accompanied by depression, and diarrhea accompanied by fever. Respiratory disease was determined by summing scores of 5 clinical signs (ocular discharge or head tilt or ear position, nasal discharge, induced or spontaneous cough, rectal temperature); each with 4 levels of severity; an abnormal respiratory score was defined as a total score of 4 or more. Navel inflammation was defined as a score of 2 or 3 (approximate width of pointer and middle fingers to width of pointer, middle, and ring fingers). Calves were considered dehydrated if skin remained tented $>4 \mathrm{~s}$. Body weight was measured on the day of arrival, 21, and $42 \mathrm{~d}$ postarrival using a digital chute scale, and ADG was calculated through 3 and 6 wh postarrival. The appetite of each calf was recorded daily following the evening milk feeding $(0=$ normal appetite; $1=$ slow consumption; $2=$ refused $<1 / 2$ of MR; $3=$ refused $>1 / 2$ of MR). Inappetence was defined as an appetite score of 3 . Mortality records through 6 wk postarrival were obtained from the producer.

Means, proportions, and standard errors were calculated for baseline characteristics. A repeated-measures ANOVA (PROC MIXED, SAS v. 9.4, SAS Institute Inc., Cary, NC) was used to compare the growth of calves on each treatment; the model included treatment and cohort as fixed effects, block as a random effect, week as a repeated measure, BW on arrival as a continuous covariate, and a treatment by week interaction. Calf was included in the model as the experimental unit. Various covariance structures were tested, and the compound symmetry covariance structure was selected based on the model fit, as assessed by the log-likelihood and Bayesian information criterion values. Additionally, the distribution of model residuals was visually assessed for normality. For descriptive purposes, the proportion of calves with at least one observed incident of diarrhea (within 5 observation days) was calculated for each treatment group, and antimicrobial use and mortality through 6 wk postarrival are also reported. A Poisson regression model (PROC GENMOD, SAS v. 9.4) was used to identify differences in the frequency (across 5 observation days) of uncomplicated and complicated diarrhea, depression, respiratory disease, navel inflammation, and dehydration. The unit of analysis was the calf, and the outcome for the model was the count of observed days with disease divided by a total of 5 calf-days at risk. Because health assessments were performed on 5 occasions (d 6, 9, 13, 16, and 22), each calf contributed a maximum of 5 calf-days. Baseline (day of arrival) health assessment variables were retained in the model if the univariable $P$-value was $<0.20$, or if inclusion of the variable changed the treatment effect measure by $>20 \%$. Cohort was included in all models as a fixed effect to account for differences between production groups. The final model for navel inflammation included treatment, cohort, and complicated diarrhea, navel inflammation, and depression on arrival as covariates. The rate ratio of uncomplicated and complicated diarrhea, depression, respiratory disease, navel inflammation, and dehydration, and the associated $95 \%$ confidence intervals for each treatment group were derived from the model using the estimate statement. Significance and tendencies were declared at $P \leq 0.05$ and $P \leq 0.10$, respectively.

Despite robust randomization procedures, the proportion of calves with abnormal depression scores on arrival differed between treatments (Table 1). Therefore, depression score on arrival was included as a covariate. The percent difference in the treatment effect with and without depression as a covariate was $<10 \%$. Packed cell volume and plasma total protein did not differ by treatment (Table 1), and $10.8 \%$ of calves had failure of passive transfer using a $5.5 \mathrm{~g} / \mathrm{dL}$ cutoff. Average BW on arrival was similar (CON: $43.1 \pm 2.7 \mathrm{~kg}$, LAC: 43.1 $\pm 3.2 \mathrm{~kg}$, CIN: $43.2 \pm 3.3 \mathrm{~kg} ; P=0.99)$, and no difference in BW at 21 and $42 \mathrm{~d}$ postarrival between treatments (Figure 1a) was detected. The ADG through 3 and 6 wk postarrival was also similar between groups (Figure 1b).

In total, $72.0 \%(54 / 75), 72.4 \%(55 / 76)$, and $72.7 \%$ $(56 / 77)$ of calves in the CON, LAC, and CIN groups, respectively, had at least one observed incident of uncomplicated diarrhea. At least one incident of diarrhea with a fever occurred in $6.67 \%(5 / 75), 14.5 \%(11 / 76)$, and $13.0 \%(10 / 77)$ of CON, LAC, and CIN calves, respectively. Further, $5.3 \%(4 / 75), 10.5 \%(8 / 76)$, and $9.1 \%(7 / 77)$ of calves in the CON, LAC, and CIN treatment groups, respectively, had at least one incident of diarrhea with depression.

Across the 5 observation days, the frequency of diagnosed uncomplicated and complicated diarrhea, depression, respiratory disease, and dehydration was not different for calves receiving lactoferrin or cinnamaldehyde compared with calves in the control treatment group (Table 2). However, CIN calves had a lower frequency of navel infections compared with CON calves (rate ratio: $0.68 ; 95 \%$ CI: 0.47 to $0.99 ; P$ $=0.04)$. The prevalence of navel infections has been included as Supplemental Table S1 (https://doi.org/ 10.3168/jds.2017-14055). No differences were observed for appetite score, suggesting neither lactoferrin nor cinnamaldehyde affected the palatability of the MR; 
a)

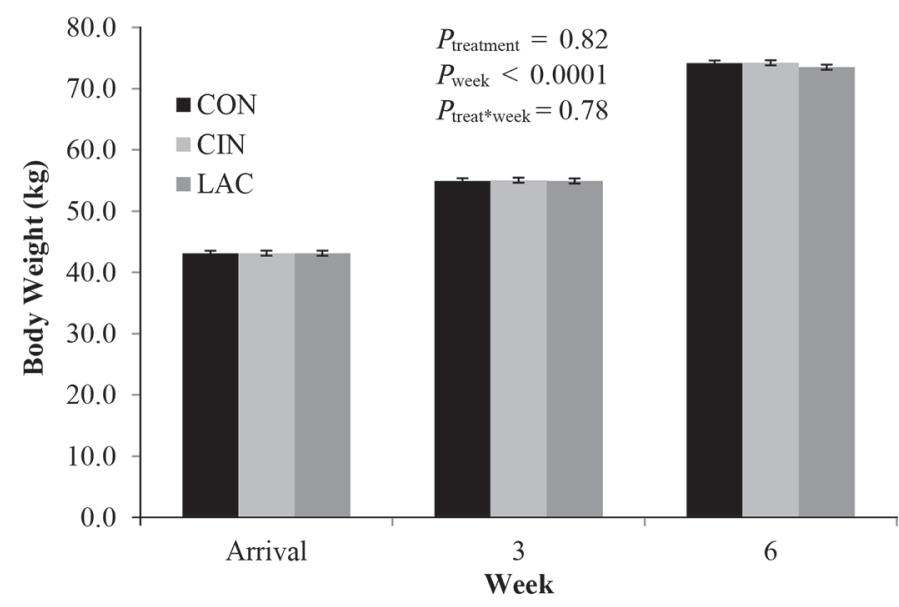

b)

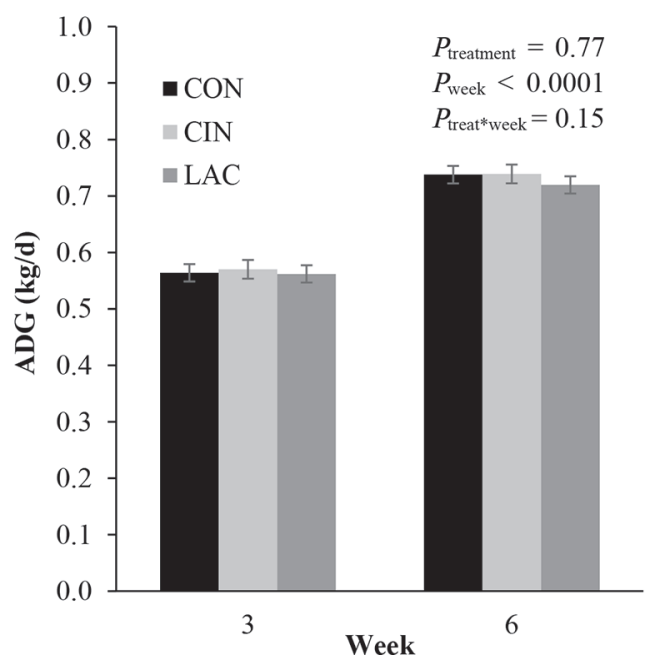

Figure 1. Body weight (a) and ADG (b; \pm SEM) of calves $(\mathrm{n}=$ 80 per treatment) for the control (CON), lactoferrin (LAC), and cinnamaldehyde (CIN) treatment groups at arrival, and 3 and 6 wk after arrival to the growing facility. treat $=$ treatment. calves only refused $>1 / 2$ MR $0.7 \%$ of the time observed (34/4,800 observations). The number of CIN, LAC, and CON calves requiring antimicrobial therapy through 6 wk postarrival were 8,11 , and 11 per treatment group, respectively. Overall reported mortality through 6 wk postarrival averaged 2.1\%; in total, 5 calves $(5 / 240)$ died or were culled before $6 \mathrm{wk}$, with 0,1 , and 4 calves from the CIN, LAC, and CON treatment groups, respectively.

Antibiotic use is necessary to ensure the health and welfare of special-fed veal calves, but unnecessary use is a major risk factor for antimicrobial resistance. Improved antimicrobial stewardship requires the investigation of alternative therapies to improve the health and growth of special-fed veal calves. To our knowledge, this is the first study to investigate supplementation of lactoferrin and cinnamandehyde on veal calf growth, health, and mortality.

In contrast to our initial hypothesis, no association was observed between supplementation and control groups in relation to $\mathrm{BW}$ or $\mathrm{ADG}$. Little research has investigated the effect of cinnamaldehyde on calf growth, but our results align with a recent study by Chapman et al. (2017) that supplemented weaned dairy heifers with lower doses of cinnamaldehyde in grain mixtures compared with $1 \mathrm{~g} / \mathrm{d}$ in MR in our study. However, prior studies have demonstrated an increase in growth of pre-weaned Holstein heifer calves supplemented with lactoferrin (Joslin et al., 2002; Robblee et al., 2003). Yet, such studies supplemented the MR with lactoferrin through weaning at approximately 4 wk of age, and lactoferrin in our study was only supplemented for $7 \mathrm{~d}$; due to logistic reasons, we were unable to extend the length of supplementation for lactoferrin and cinnamaldehyde. Moreover, it is possible that supplementation may have had longer-term treatment effects (e.g., through harvest at $20 \mathrm{wk}$ ) that were not captured by our study design.

The results of our study showed no difference in the incidence of uncomplicated or complicated diarrhea

Table 1. Health characteristics of veal calves $(n=80$ per treatment) at arrival to the growing facility for control $(\mathrm{CON})$, lactoferrin (LAC), and cinnamaldehyde (CIN) treatment groups

\begin{tabular}{|c|c|c|c|c|c|}
\hline Variable & $\mathrm{CON}$ & LAC & CIN & $\mathrm{SE}$ & $P$-value \\
\hline Packed cell volume (\%) & 32.1 & 31.0 & 31.9 & 0.75 & 0.55 \\
\hline Plasma total protein $(\mathrm{g} / \mathrm{dL})$ & 6.47 & 6.37 & 6.40 & 0.08 & 0.67 \\
\hline Mean rectal temperature $\left({ }^{\circ} \mathrm{C}\right)$ & 39.1 & 39.0 & 39.1 & 0.09 & 0.16 \\
\hline Uncomplicated diarrhea $^{1}$ (no., \%) & $9(11.3)$ & $7(8.75)$ & $8(10.0)$ & - & 0.87 \\
\hline \multicolumn{6}{|l|}{ Complicated diarrhea } \\
\hline Diarrhea + depression (no., \%) & $0(0.00)$ & $1(1.25)$ & $2(2.50)$ & - & 0.37 \\
\hline Diarrhea + fever (no., \%) & $4(5.00)$ & $4(5.00)$ & $5(6.25)$ & - & 0.92 \\
\hline Dehydration (skin tent $>4$ s; no., \%) & $25(31.3)$ & $33(41.2)$ & $30(37.5)$ & - & 0.45 \\
\hline Depression ( score $\geq 2$; no., $\%$ ) & $1(1.25)$ & $6(7.50)$ & $9(11.3)$ & - & 0.04 \\
\hline Navel inflammation (score $\geq 2 ;$ no., $\%$ ) & $22(27.5)$ & $22(27.5)$ & $27(33.8)$ & - & 0.63 \\
\hline
\end{tabular}

${ }^{1}$ Uncomplicated diarrhea defined as diarrhea (fecal score of 2 or 3 ) without fever or depression. 
Table 2. Effect of treatment with lactoferrin (LAC) or cinnamaldehyde (CIN) on the relative risk of diarrhea, dehydration, depression, navel inflammation, and respiratory disease in reference to the control group; $\mathrm{n}=80$ calves per treatment

\begin{tabular}{|c|c|c|c|c|}
\hline \multirow[b]{2}{*}{ Variable } & \multicolumn{2}{|c|}{$\mathrm{LAC}$} & \multicolumn{2}{|l|}{ CIN } \\
\hline & $\begin{array}{c}\text { Rate ratio } \\
(95 \% \text { CI })\end{array}$ & $P$-value & $\begin{array}{c}\text { Rate ratio } \\
(95 \% \mathrm{CI})\end{array}$ & $P$-value \\
\hline Uncomplicated diarrhea $^{1}$ & $1.06(0.80,1.40)$ & 0.69 & $0.93(0.69,1.24)$ & 0.61 \\
\hline \multicolumn{5}{|l|}{ Complicated diarrhea } \\
\hline Diarrhea + depression & $1.88(0.65,5.44)$ & 0.24 & $0.86(0.26,2.86)$ & 0.81 \\
\hline Diarrhea + fever & $1.96(0.74,5.21)$ & 0.18 & $1.58(0.57,4.37)$ & 0.38 \\
\hline Dehydration & $1.08(0.80,1.46)$ & 0.61 & $1.02(0.75,1.40)$ & 0.89 \\
\hline Depression & $1.24(0.64,2.42)$ & 0.52 & $0.83(0.40,1.71)$ & 0.61 \\
\hline Navel inflammation & $0.82(0.57,1.17)$ & 0.27 & $0.68(0.47,0.99)$ & 0.04 \\
\hline Respiratory disease & $0.93(0.41,2.11)$ & 0.86 & $0.86(0.37,2.01)$ & 0.73 \\
\hline
\end{tabular}

${ }^{1}$ Uncomplicated diarrhea defined as diarrhea (fecal score of 2 or 3 ) without fever or depression.

through 3 wk postarrival in veal calves supplemented with lactoferrin or cinnamaldehyde. This lack of association could be due to a variety of factors, including a shorter duration of supplementation compared with previous studies (Joslin et al., 2002; Prenner et al., 2007), variation in MR composition (e.g., antibiotics), or differences in the early management of dairy and veal production systems. In contrast to our results, Prenner et al. (2007) reported lower incidence of disease and fewer severe cases of diarrhea when calves were offered colostrum ad libitum for $6 \mathrm{~d}$, with lactoferrin supplementation from 3 to $70 \mathrm{~d}$ of age. This practice, however, would be difficult to implement in the veal industry, as little is known regarding the management of calves before arrival to the growing facility at $5 \mathrm{~d}$ of age, on average. Further, Escherichia coli commonly causes diarrhea in calves within $4 \mathrm{~d}$ of age, and colonization occurs soon after birth (Foster and Smith, 2009). Thus, it is possible that E. coli colonization has been established before arrival to the growing facility, and lactoferrin may be less effective in reducing the incidence of $E$. coli diarrhea.

Cinnamaldehyde reduced the risk of navel inflammation compared with calves in the control group. Navel inflammation is a common health concern observed in veal calves on arrival to the growing facility (Wilson et al., 2000; Pempek et al., 2017). Cinnamaldehyde has been shown to inhibit pro-inflammatory cytokines in vitro (Chao et al., 2008). Thus, supplementing veal calves with cinnamaldehyde early in the grow cycle may reduce the risk of navel inflammation and ultimately the number of antimicrobials used to treat infection. Additional studies are necessary to substantiate the effects of cinnamaldehyde for the prevention of navel inflammation in special-fed veal calves.

In conclusion, supplementing lactoferrin $(1 \mathrm{~g} / \mathrm{d}$ for 7 d) or cinnamaldehyde ( $1 \mathrm{~g} / \mathrm{d}$ for $21 \mathrm{~d})$ in MR for special-fed veal calves did not affect growth, incidence of uncomplicated or complicated diarrhea, or relative risk of diarrhea, respiratory disease, dehydration, or depression through 3 wk postarrival in our study. However, calves that received cinnamaldehyde had a lower risk of navel inflammation compared with calves in the control group. Mortality through 6 wk postarrival was low (2.1\%), and was not different across treatment groups. More research is needed to determine if a different dose, route, or duration of lactoferrin and cinnamaldehyde treatment yields longer-term effects in special-fed veal calves.

\section{ACKNOWLEDGMENTS}

This project was funded by Health Aging Nutrition, LLC; student stipend support was sponsored by Merial. We thank Atlantic Veal \& Lamb, LLC for providing access to their calves and for their help with data collection. We also thank Deanna Trearchis, Holden Hutchinson, and Danielle Coleman from The Ohio State University (Columbus), and Catie Cramer from the University of Wisconsin (Madison) for their help with data collection.

\section{REFERENCES}

Chao, L. K., K. F. Hua, H. Y. Hsu, S. S. Cheng, I. F. Lin, C. J. Chen, S. T. Chen, and S. T. Chang. 2008. Cinnamaldehyde inhibits proinflammatory cytokines secretion from monocytes/macrophages through suppression of intracellular signaling. Food Chem. Toxicol. 46:220-231.

Chapman, C. E., H. Chester-Jones, D. Ziegler, J. A. Clapper, and P. S. Erickson. 2017. Effects of cinnamaldehyde or monensin on performance of weaned Holstein dairy heifers. J. Dairy Sci. 100:17121719 .

Cowles, K. E., R. A. White, N. L. Whitehouse, and P. S. Erickson. 2006. Growth characteristics of calves fed an intensified milk replacer regimen with additional lactoferrin. J. Dairy Sci. 89:48354845.

Dohoo, I., W. Martin, and H. Stryhn. 2009. Veterinary Epidemiologic Research. 2nd ed. AVC, inc, Charlottetown, Prince Edward Island, Canada. 
Fecteau, G., J. Pare, D. C. Van Metre, B. P. Smith, C. A. Holmberg, W. Guterbock, and S. Jang. 1997. Use of a clinical sepsis score for predicting bacteremia in neonatal dairy calves on a calf rearing farm. Can. Vet. J. 38:101-104.

Foster, D. M., and G. W. Smith. 2009. Pathophysiology of diarrhea in calves. Vet. Clin. North Am. Food Anim. Pract. 25:13-36.

Habing, G., K. Harris, G. M. Schuenemann, J. M. Piñeiro, J. Lakritz, and X. Alcaraz Clavijo. 2017. Lactoferrin reduces mortality in preweaned calves with diarrhea. J. Dairy Sci. 100:3940-3948.

Joslin, R. S., P. S. Erickson, H. M. Santoro, N. L. Whitehouse, C. G. Schwab, and J. J. Rejman. 2002. Lactoferrin supplementation to dairy calves. J. Dairy Sci. 85:1237-1242.

Lago, A., S. M. McGuirk, T. B. Bennett, N. B. Cook, and K. V. Nordlund. 2006. Calf respiratory disease and pen microenvironments in naturally ventilated calf barns in winter. J. Dairy Sci. 89:4014-4025.

Mzyk, D. A., R. Gehring, L. A. Tell, T. W. Vickroy, J. E. Riviere, G. Ragan, R. E. Baynes, and G. W. Smith. 2017. Considerations for extralabel drug use in calves. J. Am. Vet. Med. Assoc. 250:12751282.

O'Connor, A. M., J. M. Sargeant, I. A. Gardner, J. S. Dickson, M. E. Torrence, C. E. Dewey, I. R. Dohoo, R. B. Evans, J. T. Gray, M. Greiner, G. Keefe, S. L. Lefebvre, P. S. Morley, A. Ramirez, W. Sischo, D. R. Smith, K. Snedeker, J. Sofos, M. P. Ward, and R. Wills. 2010. The REFLECT statement: methods and processes of creating reporting guidelines for randomized controlled trials for livestock and food safety by modifying the CONSORT statement. Zoonoses Public Health 57:95-104.

Pardon, B., B. Catry, J. Dewulf, D. Persoons, M. Hostens, K. De Bleecker, and P. Deprez. 2012. Prospective study on quantitative and qualitative antimicrobial and anti-inflammatory drug use in white veal calves. J. Antimicrob. Chemother. 67:1027-1038.

Pardon, B., M. Hostens, L. Duchateau, J. Dewulf, K. De Bleecker, and P. Deprez. 2013. Impact of respiratory disease, diarrhea, otitis and arthritis on mortality and carcass traits in white veal calves. BMC Vet. Res. 9:79.

Pempek, J., D. Trearchis, M. Masterson, G. Habing, and K. Proudfoot. 2017. Veal calf health on the day of arrival at growers in Ohio. J. Anim. Sci. 95:3863-3872.
Perino, L. J., and M. D. Apley. 1998. Clinical trial design in feedlots. Pages 343-365 in Veterinary Clinics of North America: Food Animal Practice. E. Hunt and G. L. Stokka, ed. W. B. Saunders Co., Philadelphia, PA.

Prenner, M. L., C. Prgomet, H. Sauerwein, M. W. Pfaffl, J. Broz, and F. J. Schwarz. 2007. Effects of lactoferrin feeding on growth, feed intake and health of calves. Arch. Anim. Nutr. 61:20-30.

Robblee, E. D., P. S. Erickson, N. L. Whitehouse, A. M. McLaughlin, C. G. Schwab, J. J. Rejman, and R. E. Rompala. 2003. Supplemental lactoferrin improves health and growth of Holstein calves during the preweaning phase. J. Dairy Sci. 86:1458-1464.

Rybarczyk, J., E. Kieckens, D. Vanrompay, and E. Cox. 2017. In vitro and in vivo studies on the antimicrobial effect of lactoferrin against Escherichia coli O157: H7. Vet. Microbiol. 202:23-28.

Taylor, J. D., R. W. Fulton, T. W. Lehenbauer, D. L. Step, and A. W. Confer. 2010. The epidemiology of bovine respiratory disease: What is the evidence for predisposing factors. Can. Vet. J. 51:1095-1102.

Terosky, T. L., L. L. Wilson, C. L. Stull, and W. R. Stricklin. 1997. Effects of individual housing design and size on special-fed Holstein veal calf growth performance, hematology, and carcass characteristics. J. Anim. Sci. 75:1697-1703.

Wall, E. H., P. H. Doane, S. S. Donkin, and D. Bravo. 2014. The effects of supplementation with a blend of cinnamaldehyde and eugenol on feed intake and milk production of dairy cows. J. Dairy Sci. 97:5709-5717.

Wilson, L. L., J. L. Smith, D. L. Smith, D. L. Swanson, T. R. Drake, D. R. Wolfgang, and E. F. Wheeler. 2000. Characteristics of veal calves upon arrival, at 28 and 84 days, and at end of the production cycle. J. Dairy Sci. 83:843-854.

World Health Organization. 2017. World Health Organization Critically Important Antimicrobials for Human Medicine -5th Rev. Accessed Jan. 5, 2018. http://who.int/foodsafety/publications antimicrobials-fifth/en/. 